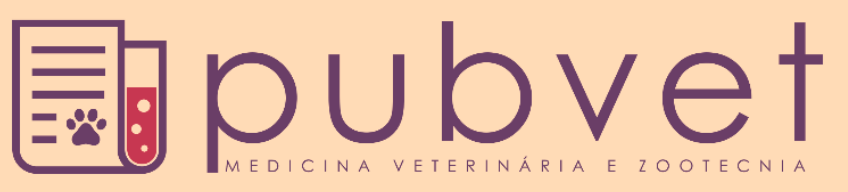

https://doi.org/10.31533/pubvet.v15n10a935.1-6

\title{
Mieloencefalite protozoária em potros: Relato de casos
}

\author{
Gislaine Gazeta de Jesus ${ }^{1}$, Regina de Cássia Veronezi ${ }^{2} \bullet$ \\ ${ }^{1}$ Médica Veterinária residente na Universidade Federal de Mato Grosso, Setor de Clínica e Cirurgia de Grandes Animais, Cuiabá, Brasil. \\ ${ }^{2}$ Docente na Universidade Federal de Mato Grosso, Setor de Clínica e Cirurgia de Grandes Animais, Cuiabá, Brasil. \\ *Autor para correspondência, E-mail: gisa_gazeta@hotmail.com
}

\begin{abstract}
Resumo. Mieloencefalite Protozoária Equina é considerada uma doença neurológia de importância onde o protozoário causador da doença é o Sarcocystis neurona e é transmitido aos equinos pela via oro-fecal por dejetos dos hospedeiros definitivos, os gambás (Didelphis virginiana e o Didelphis albiventris). A doença causa quadro neurológico nos equinos devido à ação direta do parasita no tecido nervoso, causando resposta inflamatória secundária e sinais clínicos como atrofia muscular assimétrica, fraqueza muscular, incoordenação motora decorrente da diminuição da propriocepção. Os sinais da doença podem variar, pois vai depender da localização da lesão (cérebro, cerebelo ou ainda medula espinhal). Foram atendidos pelo Hospital Veterinário da Universidade de Mato Grosso, dois equinos portadores da doença. $\mathrm{O}$ tratamento de escolha foi realizado por meio de toltrazuril, sulfa/trimetoprim, anti-inflamatórios não esteroidais, tiocolchicosido e vitamina E e selênio. Contudo, a melhor forma de prevenção é evitar a contaminação do alimento pelo hospedeiro definitivo.
\end{abstract}

Palavras-chave: Equino, mimieloencefalite, protozoário, sarcocystis neurona

\section{Protozoal myeloencephalitis in foals: Case report}

\begin{abstract}
Equine protozoan myeloencephalitis is considered a neurological disease of importance. The protozoan that causes the disease is Sarcocystis neurona and is transmitted to horses via the oro-fecal route through the waste of the definitive hosts, the possums (Didelphis virginiana and Didelphis albiventris). The disease causes neurological symptoms in horses due to the direct action of the parasite on the nervous tissue, causing secondary inflammatory response and clinical signs such as asymmetric muscle atrophy, muscle weakness, motor incoordination resulting from decreased proprioception. The signs of the disease may vary, as it will depend on the location of the lesion (brain, cerebellum or even spinal cord). Two horses with the disease attended the Veterinary Hospital of the University of Mato Grosso. The treatment of choice was carried out using toltrazuril, sulfa / trimethoprim, non-steroidal anti-inflammatory drugs, thiocolchicoside and vitamin $\mathrm{E}$ and selenium. However, the best form of prevention is to avoid contamination of the food by the definitive host.
\end{abstract}

Keywords: Equine, myeloencephalitis, protozoan, sarcocystis neurona

\section{Introdução}

A Mieloencefalite protozoária equina ((EPM) é causada pelos protozoários Sarcocystis neurona, Neospora caninum e Neospora huguesi, sendo a forma neurológica, causada pelo Sarcocystis neurona, uma das enfermidades mais frequentemente diagnosticadas em cavalos da América do Norte e Brasil (Stelmann \& Amorim, 2010). Os equinos são considerados hospedeiros intermediários aberrantes e infectam-se acidentalmente por meio de alimentos contaminados com fezes dos gambás, que são considerados hospedeiros definitivos. Esses, por sua vez, infectam-se pela ingestão de sarcocistos 
oriundos de tecido muscular de hospedeiro intermediário infectado (Cutler et al., 2001; MacKay, 2005), sendo possível citar uma variedade de mamíferos como, tatus, gatos, marsupiais, além de pássaros e dos insetos, que atuam como hospedeiro de transporte (Vilela et al., 2018). Os equinos são considerados hospedeiros aberrantes terminais, pois não foram encontrados sarcocistos do protozoário em sua musculatura, excluindo a possibilidade da transmissão do parasita para o hospedeiro definitivo (Stelmann \& Amorim, 2010). Em equinos, a infecção por S. neurona afeta o sistema nervoso central resultando em incoordenação motora, fraqueza muscular e diminuição da propriocepção (Peixoto et al., 2003). Segundo Stelmann \& Amorim (2010), embora seja grande o número de cavalos soropositivos, muitos são capazes de combater o parasita sem a necessidade de tratamento, enquanto a minoria desenvolve sinais clínicos da doença.

De acordo com Peixoto et al. (2003), uma vacina contra EPM, produzida a partir de protozoários mortos vem sendo estudada e não provoca efeitos colaterais, porém ainda está sendo testada quanto à sua eficácia e potencial. A recomendação para o protocolo vacinal consiste em duas aplicações, com a segunda dose de três a seis semanas após a primeira e com reforço anual, porém a vacina atualmente está liberada apenas nos Estados Unidos.

\section{Relato de casos}

\section{Caso 1}

Uma potra, Quarto de Milha, com oito meses e $180 \mathrm{~kg}$, oriunda do Município de Santo Antônio de Lerverger/MT foi atendida na propriedade pela equipe do setor de grandes animais do Hospital Veterinário (HOVET) da Universidade Federal de Mato Grosso, Cuiabá/MT, com suspeita de lesão neurológica.

Segundo o responsável, o animal apresentava seis dias de evolução do quadro clínico, iniciando com andar cambaleante, fraqueza, tropeços e arrastar as pinças dos cascos ao caminhar, evoluindo rapidamente para perda de equilíbrio e decúbito esternal. $\mathrm{O}$ animal não tinha histórico de vacinação, porém o controle de ecto e endoparasitos estava atualizado.

Durante o exame físico e tentativa de colocar o animal em posição quadrupedal, observou-se intensa ataxia e paresia, principalmente dos membros pélvicos, ausência de propriocepção e sinais de atrofia muscular focal do quadríceps e glúteo do lado direito, mantendo-se em decúbito esternal. A potra estava alerta, responsiva ao ambiente, com ingestão de alimento e água, porém com sinais de desidratação moderada. Observou-se ainda, taquicardia, taquipneia, tempo de preenchimento capilar de 3 segundos, mucosa levemente hiperêmica, hipomotilidade gastrointestinal e escaras de decúbito. Fezes e urina não foram observadas no momento do atendimento inicial.

Laboratorialmente, foi observado discreta anemia, rritrócitos $=6,1 \times 10^{6} / \mu \mathrm{l}$, hemoglobina 10,2 $\mathrm{g} / \mathrm{dl}$, hematócrito $=30,1 \%$ e elevação dos níveis séricos de aspartato aminotransferase (AST $=1.115 \mathrm{UI} / \mathrm{L})$ e creatinofosfoquinase $(\mathrm{CPK}=15.000 \mathrm{UI} / \mathrm{L})$.

A terapia utilizada como antiprotozoário foi toltrazuril $(7,5 \mathrm{mg} / \mathrm{kg})$, durante 60 dias, vitamina $\mathrm{E}$ e selênio $(10 \mathrm{ml})$ e firocoxibe $(0,1 \mathrm{mg} / \mathrm{kg})$ por via oral, SID, todos por 30 dias consecutivos. Dimetilsufóxido (1 mg/kg), sulfa/trimetropim $(15 \mathrm{mg} / \mathrm{kg})$ e flunixin meglumine $(1,1 \mathrm{mg} / \mathrm{kg})$, via endovenosa SID por três, sete e cinco dias, respectivamente. Além disso, foi administrado omeprazol (2 $\mathrm{mg} / \mathrm{kg}$ ) por sete dias, e tiocoolchicosídeo $(0,05 \mathrm{mg} / \mathrm{kg})$ durante cinco dias, ambos por via oral SID. O firocoxibe foi iniciado após o término de flunixin meglumine. Para as escaras de decúbito foi utilizado óleo de girassol após a limpeza com solução antisséptica, até a total cicatrização. Como fluidoterapia de suporte, optou-se pelo ringer com lactato até a melhora do quadro clínico. A evolução do quadro clínico após início da terapia, encontra-se demonstrado nas figuras 1 e 2 .

\section{Caso 2}

Uma potra, Quarto de Milha, doce meses de idade e $185 \mathrm{~kg}$, proveniente do Município de São José do Rio Claro/MT, foi admitida no HOVET com suspeita de intoxicação alimentar.

O proprietário relatou que o animal estava com andar cambaleante, arrastando as pinças dos cascos e aparentando fraqueza ao caminhar. Desta forma, o mesmo suspeitou de intoxicação alimentar devido 
o animal ter ingerido ração destinada a alimentação de frangos, no entanto, não soube informar a quantidade.

Segundo ele, o quadro evoluiu rapidamente nas primeiras 24 horas, e a potra passou a ficar em decúbito esternal contínuo, sendo fornecido feno e água a vontade, com boa ingestão. A micção e defecação estavam normais. O esquema vacinal e o controle parasitário estavam desatualizados. $\mathrm{Na}$ admissão, o animal estava no $6^{\circ}$ dia de evolução do quadro clínico, em decúbito lateral, apática, com mucosa oral e ocular hiperêmicas, TPC de três segundos, taquicardia, taquipneia e $\mathrm{T}^{\circ} \mathrm{C} 38,7$, com timpanismo bilateral e hipomotilidade gastrointestinal, e desidratação estimada em 5\%. Apesar da apatia, ela estava alerta e responsiva ao ambiente e a estímulos, porém com intensa paresia de membros pélvicos, com impossibilidade de se manter em posição quadrupedal, alternando entre decúbito lateral e esternal.

O apetite estava sempre presente, com boa ingestão de feno, alfafa e ração comercial (1/2 kg BID). Micção e defecação normais, contudo, com a presença de grade quantidade de Oxyuris equi nas fezes. Foi encaminhado material para hemograma e exame bioquímico, onde se observou anemia, eritrócitos $=5,61 \times 10^{6} / \mu \mathrm{l}$, hemoglobina 7,5 g/dl, hematócrito $=21,6 \%$ e aumento dos níveis séricos de aspartato aminotransferase $(\mathrm{AST}=836 \mathrm{UI} / \mathrm{L})$ e creatinofosfoquinase $(\mathrm{CPK})=10.351 \mathrm{UI} / \mathrm{L})$.

De acordo com a similaridade do quadro clínico em ambos os casos e a suspeita de EPM, foi estabelecida a mesma terapia. Utilizou-se toltrazuril $(7,5 \mathrm{mg} / \mathrm{kg})$, durante 60 dias, vitamina E e selênio $(10 \mathrm{ml})$ e firocoxibe $(0,1 \mathrm{mg} / \mathrm{kg})$ por via oral, SID, todos por 30 dias consecutivos. Dimetilsufóxido (1 $\mathrm{mg} / \mathrm{kg})$, sulfa/trimetropim $(15 \mathrm{mg} / \mathrm{kg})$ e flunixin meglumine $(1,1 \mathrm{mg} / \mathrm{kg})$, via endovenosa SID por três, sete e cinco dias, respectivamente. Além disso, foi administrado omeprazol $(2 \mathrm{mg} / \mathrm{kg})$ por sete dias, e tiocoolchicosídeo $(0,05 \mathrm{mg} / \mathrm{kg})$ durante cinco dias, ambos por via oral SID. O firocoxibe foi iniciado após o término de flunixin meglumine. Para as escaras de decúbito foi utilizado óleo de girassol após a limpeza com solução antisséptica, até a total cicatrização. Como fluidoterapia de suporte, optou-se pelo ringer com lactato até a melhora do quadro clínico. Nas figuras 3 e $\underline{4}$ é possível notar a evolução do quadro clínico após terapia.

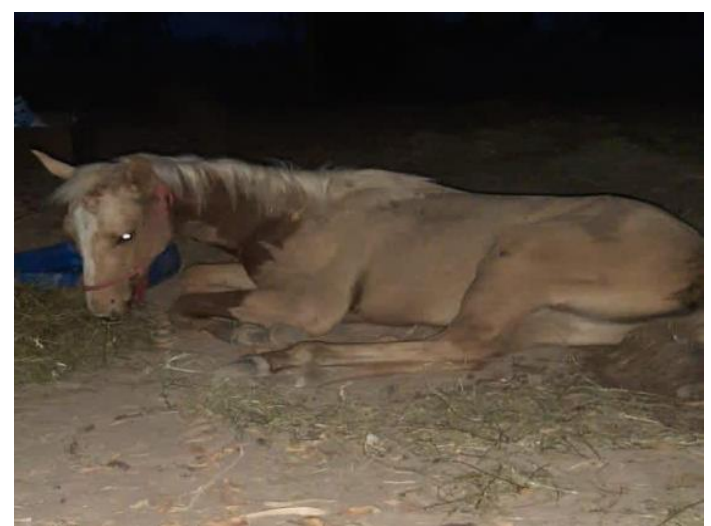

Figura 1. Potra no primeiro dia de tratamento da Mieloencefalite protozoária equina

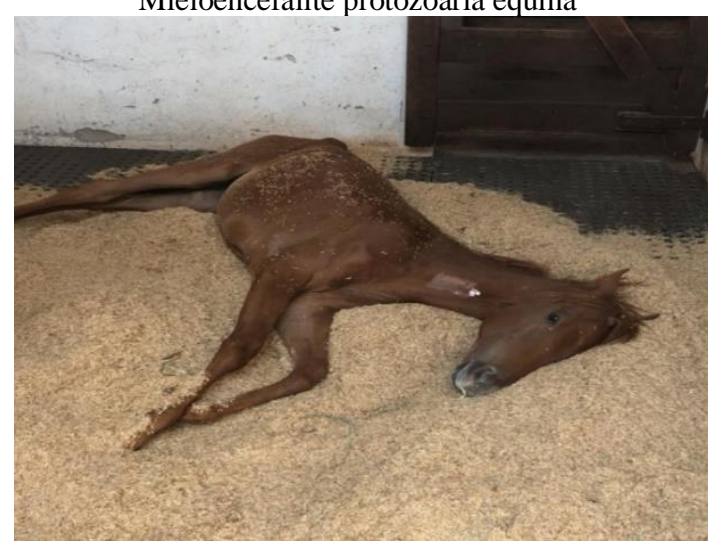

Figura 3. Potra no primeiro dia de tratamento da Mieloencefalite protozoária equina

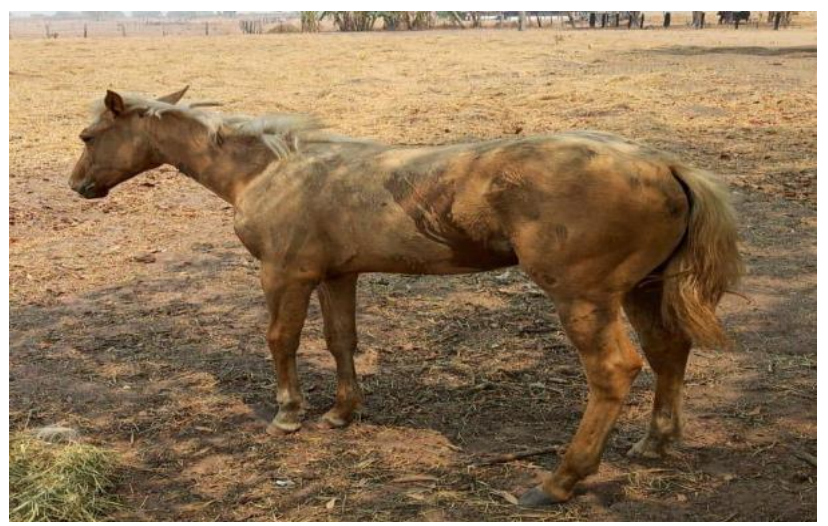

Figura 2. Potra no sexto dia de tratamento da Mieloencefalite protozoária equina

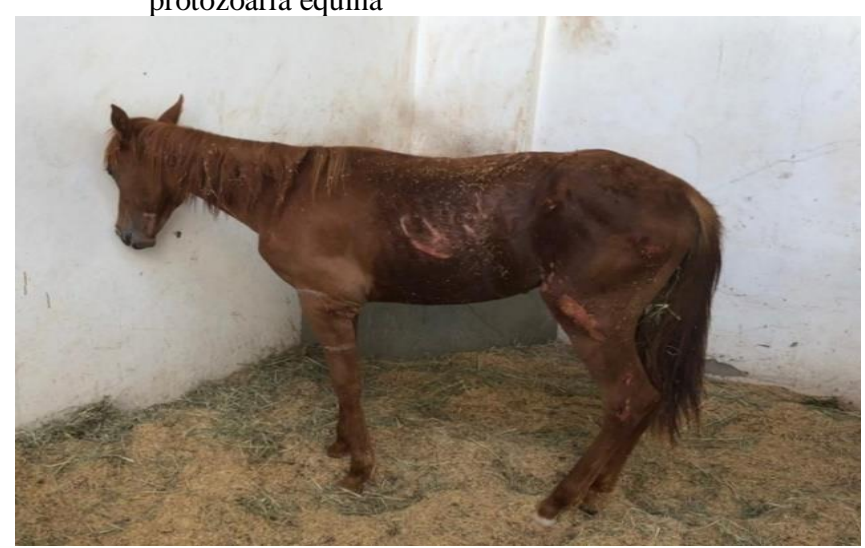

Figura 4. Potra no sexto dia de tratamento da Mieloencefalite protozoária equina 


\section{Resultados e discussão}

Levando em consideração a importância da EPM no contexto das doenças neurológicas, os autores Stelmann \& Amorim (2010) descrevem que à associação da infecção à reação inflamatória, provoca alteração na função neurológica normal, observando-se sinais de fraqueza, atrofia muscular e déficits proprioceptivos.

Os casos relatados abordaram os aspectos clínicos e terapêuticos da doença causada pelo Sarcocystis neurona. Condizente com a descrição de Thomassian $(\underline{2005})_{2}$ no exame físico, observou-se intensa ataxia e paresia, principalmente dos membros pélvicos, ausência de propriocepção e sinais de atrofia muscular focal do quadríceps e glúteo unilateral, em ambos os casos, observados do lado direito. Alterações encefálicas também podem ser observadas, afetando os nervos cranianos causando paralisia do nervo facial, desvio de cabeça, atrofia ou paralisia do masseter, perda de sensibilidade das narinas e córneas, porém essas alterações não foram encontradas nos animais avaliados.

Nos casos em que há evidências de lesão na medula sacral, pode-se observar paresia da cauda, incontinência urinária e relaxamento do esfíncter anal (Radostits et al., 2010), sinais estes, não encontrados nos casos relatados. A apresentação clássica da doença é incoordenação motora assimétrica, atrofia muscular focal, diminuição proprioceptiva e paresia, geralmente mais graves nos membros posteriores (Fenger et al., 1997). O andar assimétrico com atrofia muscular focal pode ajudar a diferenciar EPM de outras afecções neurológicas (Dubey et al., 1991). Os principais diagnósticos diferenciais da EPM são: raiva, mielopatia estenótica cervical, mieloencefalopatia degenerativa equina, mieloencefalopatia com neurite/vasculite causada pelo Herpesvírus equino do tipo 1 e trauma (Stelmann \& Amorim, 2010).

A EPM não produz alterações consistentes no hemograma ou na bioquímica sérica (MacKay, 1997), embora pode-se observar que os animais encontravam-se anêmicos e as enzimas teciduais como a AST e CPK estavam muito elevadas, possivelmente relacionadas com estresse, traumas (MacKay, 2006; MacKay et al., 2000), e danos musculares secundários a lesão neurológica (Peixoto et al., 2003).

Nestes casos, a suspeita diagnóstica de EPM foi baseada no histórico, nos sinais clínicos, na exclusão de outras enfermidades e na resposta à terapia, bem como na evolução do quadro clínico. Normalmente os animais acometidos apresentam progressão gradativa dos sinais clínicos. Entretanto, em alguns casos, o aparecimento gradual pode dar lugar a um agravamento súbito no quadro clínico, resultando em decúbito. De acordo com o histórico, nos dois casos o quadro clínico foi agudo e progressivo, evoluindo de incoordenação motora, principalmente dos membros pélvicos, a decúbito permanente no mesmo dia (MacKay et al., 2000). Devido à rápida evolução e piora do quadro, optou-se por iniciar a terapia preconizada para EPM como descrito por Dubey et al. (2001), que indica iniciar o tratamento do animal suspeito assim que os sinais clínicos forem observados. Os testes de diagnóstico de eleição para EPM é o Western Blot, segundo Gardner et al. (2003); contudo, devido a gravidade dos casos, seria inviável o tempo de espera pelo resultado, pois teria que encaminhar amostra para outra cidade. De acordo com MacKay et al. (2000). Métodos sorológicos e PCR também são formas de diagnóstico; contudo, a sensibilidade da PCR para a EPM é baixa, pois as enzimas presentes no líquido cefalorraquidiano (LCR) podem destruir rapidamente o DNA do parasita ou até mesmo pela escassez de DNA (Dubey et al., 2001; MacKay et al., 2000).

O tratamento foi realizado com base na utilização de antimicrobianos e drogas antiprotozoárias (coccidiostáticos), além disso, o uso de anti-inflamatórios, imunomoduladores e antioxidantes, conforme preconizado por com Stashak (2011). A administração sulfa/trimetropim foi eleita como antimicrobiano, se deu pelo fato de atuar diretamente sobre o parasita (Peixoto et al., 2003). O toltrazuril foi o coccidiostático de escolha para o tratamento, sendo amplamente utilizado em várias espécies. $\mathrm{O}$ seu mecanismo de ação incide em desestabilizar a divisão celular e o metabolismo do parasita, mostrando alta eficácia para o tratamento de EPM, com boa absorção oral e no LCR (Vilela et al., 2018). Para Furr \& Kennedy (2000), a resposta ao tratamento com o toltrazuril é ligeiramente melhor se comparada a outras terapias, pois segundo os autores, o índice de recuperação após o tratamento com sulfa/trimetoprim associado à pirimetamina é de $30 \%$, enquanto com o tratamento utilizando toltrazuril é de $73 \%$ de recuperação, devido a maior absorção pelo LCR. Foi estabelecido o uso de Flunixin Meglumine e dimetilsulfóxido, justificou-se para abrandar os fenômenos inflamatórios do sistema 
nervoso central (Thomassian, 2005). A suplementação com vitamina E e Selênio como imunomodulador e antioxidante, respectivamente, foi realizada visando as propriedades antiinflamatórias em quando em altas concentrações no SNC (Peixoto et al., 2003).

O tiocoolchicosídeo foi utilizado como miorrelaxante, a fim de promover conforto aos animais e omeprazol como protetor de mucosa. As duas potras responderam de forma favorável e gradativa ao uso do toltrazuril e da medicação de suporte associada, conseguindo ficar em posição quadrupedal com auxílio médico após quatro dias do início da terapia. Inicialmente, a troca de decúbito foi realizada três vezes ao dia, e a manipulação na tentativa de deixar os animais em estação, duas vezes ao dia, até que pudessem se levantar sozinhos, o que ocorreu no $4^{\circ}$ dia, como descrito acima. Nesse período, as duas potras apresentaram normalidade para os sinais vitais, ingestão alimentar e hídrica, fezes e urina, além de se manterem dispostas e alertas (Stelmann \& Amorim, 2010). Portanto, os animais deste relato, se recuperam totalmente não apresentando sequelas.

\section{Considerações finais}

Após o relato, confirma-se que a EPM é uma doença causada pelo Sarcocistys neurona, um coccídio, que causa lesão no SNC dos equinos, é infecciosa e não contagiosa, caracterizada principalmente por sinais de ataxia, incoordenação motora e atrofia muscular do animal.

A restrição aos alimentas contaminados por dejetos dos hospedeiros definitivos, minimizam a incidência desta patologia aos equinos, sendo essa então, a melhor forma de prevenção.

A opção por se instituir rapidamente o tratamento foi de suma importância devido à gravidade dos quadros. Além do mais, a terapia de escolha se mostrou eficaz contra a doença pois houve rápida recuperação dos animais relatados em curto espaço de tempo e os mesmos, por sua vez, não ficaram com sequelas.

\section{Referências bibliográficas}

Cutler, T. J., MacKay, R. J., Ginn, P. E., Gillis, K., Tanhauser, S. M., LeRay, E. V, Dame, J. B., \& Greiner, E. C. (2001). Immunoconversion against Sarcocystis neurona in normal and dexamethasone-treated horses challenged with S. neurona sporocysts. Veterinary Parasitology, 95(2-4), 197-210.

Dubey, J. P., Davis, S. W., Speer, C. A., Bowman, D. D., De Lahunta, A., Granstrom, D. E., Topper, M. J., Hamir, A. N., Cummings, J. F., \& Suter, M. M. (1991). Sarcocystis neurona n. sp.(Protozoa: Apicomplexa), the etiologic agent of equine protozoal myeloencephalitis. The Journal of Parasitology, 212-218.

Dubey, J. P., Lindsay, D. S., Saville, W. J. A., Reed, S. M., Granstrom, D. E., \& Speer, C. A. (2001). A review of Sarcocystis neurona and equine protozoal myeloencephalitis (EPM). Veterinary Parasitology, 95(2-4), 89-131.

Fenger, C. K., Granstrom, D. E., Gajadhar, A. A., Williams, N. M., McCrillis, S. A., Stamper, S., Langemeier, J. L., \& Dubey, J. P. (1997). Experimental induction of equine protozoal myeloencephalitis in horses using Sarcocystis sp. sporocysts from the opossum (Didelphis virginiana). Veterinary Parasitology, 68(3), 199-213.

Furr, M., \& Kennedy, T. (2000). Cerebrospinal fluid and blood concentrations of toltrazuril 5\% suspension in the horse after oral dosing. Veterinary Therapeutics: Research in Applied Veterinary Medicine, 1(2), 125-132.

Gardner, P., Conrad, A. P., Dfat, M. B., \& Duarte, P. C. (2003). Comparação de um teste de imunofluorescência indireta com dois testes de Western blot para o diagnóstico de mieloencefalite protozoária equina. Journal of Veterinary, 158, 8-13.

MacKay, R J. (1997). Equine protozoal myeloencephalitis. Veterinary Clinics of North America-Equine Practice, 13(1), 79-96.

MacKay, R J. (2006). Equine protozoal myeloencephalitis: treatment, prognosis, and prevention. Clinical Techniques in Equine Practice, 5(1), 9-16.

MacKay, Robert J. (2005). Neurologic disorders of neonatal foals. Veterinary Clinics: Equine Practice, 
21(2), 387-406.

MacKay, Robert J, Granstrom, D. E., Saville, W. J., \& Reed, S. M. (2000). Equine protozoal myeloencephalitis. Veterinary Clinics of North America: Equine Practice, 16(3), 405-425.

Peixoto, A. P. C., Kuchembuck, M. R. G., Gonçalves, R. C., Chiacchio, S., Kohayagawa, A., \& Castro, A. A. P. (2003). Mieloencefalite protozoária eqüina (Relato de caso). Revista Brasileira de Saúde e Produção Animal, 4(1), 30-34.

Radostits, O. M., Gay, C. C., Blood, D. C., Hinchcliff, K. W., \& McKenzie, R. A. (2010). Clínica Veterinária: um tratado de doenças dos bovinos, ovinos, suínos, caprinos e eqüinos (Vol. 1). Guanabara Koogan.

Stashak, T. S. (2011). Claudicação em eqüinos segundo Adams. Editora Roca.

Stelmann, U. J. P., \& Amorim, R. M. (2010). Mieloencefalite protozoária equina. Veterinária e Zootecnia, 17(2), 163-176.

Thomassian, A. (2005). Enfermidades dos cavalos. Livraria Varela.

Vilela, S. E. R., Oliveira, P. G., Moreira, C. N., Saturnino, K. C., Viu, M. A. O., Ribeiro, D. da S. F., \& Ramos, D. G. S. (2018). Mieloencefalite protozoária equina (Sarcocystis neurona e Neospora hughesi): Revisão. PUBVET, 13(1), 1-11. https://doi.org/10.31533/pubvet.v13n01a246.1-11.

Histórico do artigo:

Recebido: 16 de abril de 2021

Aprovado: 9 de junho de 2021
Licenciamento: Este artigo é publicado na modalidade Acesso Aberto sob a licença Creative Commons Atribuição 4.0 (CC-BY 4.0), a qual permite uso irrestrito, distribuição, reprodução em qualquer meio, desde que o autor e a fonte sejam devidamente creditados. 